\title{
Interactive QuickTime: Developing and Evaluating Multimedia Learning Objects to Enhance Both Face-To-Face and Distance E-Learning Environments
}

\author{
Thomas Cochrane, Unitec, Auckland, New Zealand
}

tcochrane@unitec.ac.nz

\begin{abstract}
This paper discusses the application of Learning Objects in supporting the teaching of principles of Audio Engineering - a subject traditionally taught face-to-face utilizing specialized audio equipment. It demonstrates how creating interactive multimedia learning objects can enhance traditional teaching methods, and potentially provide virtual learning environments for online delivery. The paper also focuses upon the application of the multimedia architecture 'QuickTime', which was chosen because of its cross-platform capability, multi platform delivery and scalability (Internet, CDROM, Hard drive...), ease of authoring, high level of interactivity possible, and excellent audio capabilities. The insights gained from developing and evaluating several interactive Learning Objects are highlighted.
\end{abstract}

Keywords: Learning Objects, QuickTime.

\section{Introduction}

\section{Defining Learning Objects}

While definitions are varied, most researchers and practitioners would agree that Learning Objects are meant to enhance learning and to be reusable within a range of learning contexts. They are usually interactive digital resources illustrating one or a few interrelated concepts. They are small in size, but contain enough content and context to make them pedagogically useful. This project uses Wiley's definition of Learning Objects as a basis:

Learning object: Any digital resource that can be reused to support learning. The term "learning objects" generally applies to educational materials designed and created in small chunks for the purpose of maximizing the number of learning situations in which the resource can be utilized (Wiley, 2002, p. 1).

Material published as part of this journal, either on-line or in print, is copyrighted by the publisher of the Interdisciplinary Journal of Knowledge and Learning Objects. Permission to make digital or paper copy of part or all of these works for personal or classroom use is granted without fee provided that the copies are not made or distributed for profit or commercial advantage AND that copies 1) bear this notice in full and 2) give the full citation on the first page. It is permissible to abstract these works so long as credit is given. To copy in all other cases or to republish or to post on a server or to redistribute to lists requires specific permission and payment of a fee. Contact Publisher@ijklo.org to request redistribution permission.

\section{Why Learning Objects?}

Learning Objects are the descendants of the computer mediated learning (CML), and interactive multimedia movements (IMM). The late twentieth century educational environment was filled with expectation at how CML and IMM would revolutionize learning. The reality was that the cost of producing highly interactive 
Interactive QuickTime

CDROMs and online courses was in most cases prohibitive. CDROMs went out of date almost as soon as they were produced, and were often far too context specific to be reused in learning environments other than the specific one they were designed for. While moving away from these initial behemoths, the last few years have seen the anticipation of how small, interactive, reusable Learning Objects will bring the cost of education down while increasing quality and access. Those with the biggest stake in the funding of education (governments and large multinational private companies) have encouraged research into the area of Learning Objects. The New Zealand government has provided significant funding for collaborative projects between tertiary education institutions in the broad area of e-learning. Developing expertise in this area is seen as a way of competing in the global education market for a geographically isolated country such as New Zealand.

The vision of the Learning Object economy (Downes, 2003; Johnson, 2003) is one where, instead of constantly re-inventing the wheel, educators can access shared online libraries of quality interactive Learning Objects to enhance the delivery of their courses and the quality of the learning experience for their students. While progress is being made, the dream is still to be realized in any major way, but it is a dream worth pursuing.

\section{The Audio Engineering Context}

Coming from a background of teaching Audio Engineering, this researcher was interested in exploring the potential of Learning Objects within this field. A search of Learning Object repositories and the Internet reveals there is a lack of quality multimedia learning resources for key Audio Engineering concepts, although some do exist (SAE Institute, 2001). Most relevant resources are text and audio based only. Online (Hambly, 2002) or CDROM examples provide little more than replacements for textbooks, although they do usually contain audio examples (Everest, 1997). There are a couple of notable exceptions (Neumann, 1996; Sides, 1995), however these are large resources that were not designed as Learning Objects. Some resources are outdated, both technically and in content, while most resources focus upon text or audio examples only, with little user interactivity. Some online examples (Gibson, 2000; Mellor, 2001, 2003) do, however, provide facilities for email and discussion group support for students. In general these resources are designed as complete unique packages or courses, and have not been designed for re-purposing in other learning contexts. The quality of available Learning Objects for this context is low, and the general mode for learning the principles of audio engineering is still an on campus/site hands on approach.

\section{The Research Objective}

There is a gap between theory and practice in the use of Learning Objects in tertiary education. Most research has focused on defining Learning Objects rather than practical design and implementation. As a result the overly hyped Learning Object economy has yet to be realized.

During the Middle Ages, theologians and philosophers spent large amounts of time debating the precise number of angels that could dance on the head of a pin. The early learning object movement has spent similarly large amounts of time debating what the correct definition of a learning object should be (Roy, 2004b, p. 1).

The objective of this research was to bridge the gap between Learning Object theory and practice by utilizing established instructional design principles to produce quality interactive Learning Objects. These resources are intended to support both distance and face-to-face learning. By using Learning Objects the learning context and outcomes will be able to be modified by educators to suit the needs of different users. 
The study breaks new ground within the context of Audio Engineering, moving beyond the established instructional pedagogy usually employed to teach basic concepts, and places interactive Learning Objects within a constructivist pedagogy.

Because the research is interested in producing change and creating usable Learning Objects the best research method fit is that of action research.

As the research project is focused upon the educational design of Learning Objects, an investigation into instructional design principles was included. While there is a great body of research applied to traditional instructional design, there is relatively little research specific to design principles for Learning Objects. "There are relatively few studies and tools relating to the systematic analysis, design and documentation that should precede construction and delivery...” (Douglas, 2001). The pedagogical usefulness of Learning Objects is a major concern of researchers. Williams (2000) argues that evaluation of Learning Objects should parallel development. He argues for a participant oriented approach to evaluation. He then embeds these evaluation processes within the ADDIE development model (Assess needs, Design, Develop, Implement, and Evaluate instruction). Williams also argues that evaluation of Learning Objects should be both 'external' and 'internal'. A similar approach to this was used in the research project.

\section{MERLOT}

One of the most mature approaches to evaluating Learning Objects is utilized by the MERLOT (1997) repository. The MERLOT Peer review process is modeled on the scholarly peer review process of peer reviewed journals (Hanley, 2003). The goal of adopting this approach to evaluation of Learning Objects is to encourage the adoption of Learning Objects within the higher education community. The MERLOT repository is divided into several subject categories/communities, with an editorial board for each category. Experts in each field are allocated to review submitted Learning Objects within each category. The result of the peer review process is a rating from one to five, plus comments for every Learning Object reviewed. The rating scale represents the following:

1. Materials not worth using at all.

2. Materials do not meet minimal standards but there might be some limited value.

3. Materials meet or exceed standards but there are some significant concerns.

4. Materials are very good overall but there are a few minor concerns.

5. Materials are excellent all around.

The ratings are used to give preferential listing in searches of the MERLOT repository, and provide users with a quick idea of the quality and usefulness of a Learning Object. Learning Objects with review grades of less than 3 are not displayed.

\section{The Research Project}

This research project involved developing and piloting multimedia Learning Objects during 2003/2004. It implements research and instructional design principles to enhance learning via multimedia Learning Objects, within a context of Audio Engineering. The project also employs an action research method implemented over a period of two years.

Current educational thought postulates that learning objects can provide the basis for reusable, pedagogically rich learning materials. The project tested these assumptions and demonstrates that although pedagogically rich learning objects are currently scarce (within New Zealand) for teaching principles of Audio Engineering, they can be designed and delivered to meet the goals of pro- 
viding reusable and pedagogically rich learning environments within this traditionally face-toface taught discipline.

The objective of this research was to utilize established instructional design principles to produce interactive learning resources based upon appropriate Learning Objects. These resources are intended to support both distance and face-to-face learning. By using Learning Objects the context and outcomes will be able to be modified by educators to suit the needs of different users. Two distinct groups of users were targeted to test the reusability of these Learning Objects: Audio Engineering tertiary students (at MAINZ - the Music \& Audio Institute of New Zealand, where the researcher taught during the implementation of this research), and Church Sound Engineers. The first group of users (MAINZ Tutors and their students) encompasses a range of Audio Engineering related courses including: Certificate of Foundation Studies in Music - Level 3, Certificate of Live Sound - Level 4, Certificate of Audio Engineering - Level 5, Diploma of Contemporary Music Performance - Level 5, and Diploma of Audio Engineering - Level 6. Different courses with different curricula and levels thus provided an indication of the reusability of the Learning Objects. The second group of users (Church Sound Engineers and their teams) consisted of representatives from five medium to large contemporary church congregations throughout Auckland. The churches included:

- Massey Community Church - congregation approximately 200

- Birkenhead Community Church - congregation approximately 300

- $\quad$ Lincoln Road Bible Chapel - congregation approximately 350

- Christian City Church - congregation approximately 400

- Christian Life Centre Auckland - congregation approximately 3000

The principal sound operator for each church was asked to evaluate each of the Learning Objects throughout the period of the study. This group was chosen as it has been noticed that there is a lack of part time or flexible training opportunities for Church Sound Engineers in New Zealand. Appropriate Learning Objects could help fill this gap. Their goals were oriented towards gaining practical skills for a specific situation (sound for Church Services) rather than meeting the demands of a tertiary curriculum like the MAINZ students, and they do not have the benefit of expert tuition or student peers.

The research involved designing and delivering, to these distinct groups of users, several appropriate Learning Objects. The users evaluated each Learning Object, over the period of a semester. Data collected from these evaluations was used to inform the development of new learning objects to be evaluated in the following semester by the same groups of users. There were four iterations of design, delivery and evaluation over the period of the study. The project provides reflective feedback from the target users for modification and development of the resources.

\section{Research Questions}

(1) What are the key factors in designing Learning Objects that are reusable for learning concepts in Audio Engineering - a discipline that traditionally teaches these concepts in a 'face-to-face' 'hands-on' mode?

(2) To what extent can these Learning Objects support learner interactivity and interest, and thus provide pedagogically rich learning environments that engage and motivate the learner? 


\section{Project Methodology}

The project is qualitative in nature, and uses a small 'sample' of participants evaluating the developed Learning Objects. The project was conducted part time over a two-year period, and used action research as its methodology, involving one research cycle per semester. The action research cycles provided time for reflection and feedback between researching and developing an appropriate interactive learning resource and trialing the resource on users. This reflection and feedback provided data on the success of the embedded pedagogy within the resource and areas needing modification. The approach of action research provides a close fit with the researcher's own view of education (transformative - seeking to produce change) and preference for qualitative rather than quantitative research. Action research also provides a close fit with the underlying philosophy of Learning Objects - constructivism (Bannan-Ritland, Dabbagh, \& Murphy, 2000). Wadsworth (1998) identifies the key characteristics of 'participatory action research' as: the researcher is a participant, the researcher is the main research instrument, it is cyclical in nature, involves action followed by reflection followed by informed action, and is concerned with producing change. This change is ongoing throughout the process, and the research is interested in input from participants/stakeholders. The design and development of Learning Objects follows the classic cyclical nature of action research, and educational research often puts the researcher in the key role of prime collector of data (Wadsworth, 1998). Qualitative research provides rich data for educational situations (Hoepfl, 1997). Data collection methods are outlined in Table 1, and included focus groups (See Appendix 2 for questions) and keeping a reflective journal.

Table 1: Data Gathering

\begin{tabular}{|l|l|}
\hline $\begin{array}{l}\text { Data gathering proc- } \\
\text { esses }\end{array}$ & Description \\
\hline Initial need analysis & $\begin{array}{l}\text { A short survey deployed to MAINZ tutors to establish the perceived } \\
\text { need for interactive Learning Objects within the context of Audio En- } \\
\text { gineering, and suggestions for concepts to be covered. }\end{array}$ \\
\hline $\begin{array}{l}\text { Diploma of Audio En- } \\
\text { gineering student } \\
\text { Evaluations }\end{array}$ & $\begin{array}{l}\text { A short evaluation sheet to gain initial feedback on the pre-release ver- } \\
\text { sions of the Learning Objects from the researchers own group of stu- } \\
\text { dents. }\end{array}$ \\
\hline $\begin{array}{l}\text { MAINZ Tutors and } \\
\text { student evaluations } \\
\text { (See Appendix 1) }\end{array}$ & $\begin{array}{l}\text { Each Learning Object was delivered to MAINZ tutors on CDROM } \\
\text { with a paper copy of the modified MERLOT evaluation form for filling } \\
\text { out. Tutors were asked to nominate a couple of students within their } \\
\text { course to evaluate the Learning Objects as well. }\end{array}$ \\
\hline $\begin{array}{l}\text { Church sound operator } \\
\text { evaluations }\end{array}$ & $\begin{array}{l}\text { Each Learning Object was delivered to selected church sound operators } \\
\text { on CDROM with a paper copy of the modified MERLOT evaluation } \\
\text { form for filling out. }\end{array}$ \\
\hline $\begin{array}{l}\text { Focus groups (See Ap- } \\
\text { pendix 2) }\end{array}$ & $\begin{array}{l}\text { Two focus groups were convened, one consisting of representatives } \\
\text { from MAINZ tutors, and the other consisting of representatives from } \\
\text { the church sound operators. }\end{array}$ \\
\hline $\begin{array}{l}\text { Web deployment of } \\
\text { Learning Objects }\end{array}$ & $\begin{array}{l}\text { The Learning Objects were progressively uploaded to an Internet server } \\
\text { for access via the Internet. }\end{array}$ \\
\hline $\begin{array}{l}\text { Feedback from over- } \\
\text { seas international ex- } \\
\text { perts }\end{array}$ & $\begin{array}{l}\text { Several international Audio experts were contacted to evaluate the } \\
\text { Learning Objects supplied on the web site, using the modified } \\
\text { MERLOT evaluation form. }\end{array}$ \\
\hline
\end{tabular}


Interactive QuickTime

\begin{tabular}{|l|l|}
\hline MERLOT evaluations & $\begin{array}{l}\text { After completion, the four Learning Objects were contributed to the } \\
\text { MERLOT repository for MERLOT peer evaluation }\end{array}$ \\
\hline Reflective Journal & A reflective journal was kept detailing key events etc of the project. \\
\hline
\end{tabular}

Evaluators were given a copy of each Learning Object on CD (cross-platform for both Macintosh and Windows operating systems), and an evaluation form. As discussed earlier, the MERLOT Learning Object evaluation criteria are well developed and have been in use for several years. It was therefore decided to use the MERLOT (2000) criteria as the basis for the evaluation of the developed Learning Objects for this research. To make the evaluation process simpler for the evaluators, the checklist version of the MERLOT evaluation criteria was used. This check list was developed as part of a conference workshop (Bennett \& Metros, 2001). The evaluation criteria are divided into questions covering the three main criteria: reusability, interactivity and pedagogy. The questions were modified for the context of this research project, and some questions were changed to better reflect the research questions of the project as well. The questions are structured as Likert scale rating responses to statements regarding the Learning Object, plus a section for long answer comments for each category. There are eight questions regarding reusability, and six questions in each of the interactivity and pedagogy categories respectively. The evaluation form questions were briefly moderated by a couple of MAINZ tutors before finalizing (See Appendix $1)$.

The goal of the project was to develop Learning Objects that were scalable for delivery over a variety of delivery formats. The Learning Objects were supplied to evaluators on CDROM, but were also made available from the Internet. As each Learning Object was developed, it was also uploaded to a web server to test its accessibility and download times over the Internet. Once all four Learning Objects were developed, a web site was created to provide access and information that could be updated as feedback was received, and any 'bugs' found in the Learning Objects could be corrected and the updated Learning Objects made available from the website. The website delivery necessitated the inclusion of metadata about the Learning Objects. A web-based form (Koch \& Borell, 1997) was used to create metadata in the Dublin Core format for each Learning Object. This metadata was included as a text document associated with each Learning object, and the meta tags generated by the online form were also pasted into the $<$ head $>$ of each web page holding the Learning Objects. This allows search engines to correctly categorize the Learning Objects. The website also provided access to the Learning Objects for the international evaluators.

Although the study is qualitative, some quantitative data and basic analysis was helpful, especially in providing a way to summarize trends and comparisons in evaluation feedback. The MERLOT evaluation process includes a numerical assignment from 1 to 5 for each evaluation question. This allows an average overall rating from 1 to 5 to be assigned to an evaluated Learning Object. This gives potential users of the Learning Objects immediate feedback as to the overall quality of the Learning Object. This practice was adopted by this study, to provide a quick comparative rating for each Learning Object. Because the MERLOT evaluation criteria questions were modified to the context of the research project, the resulting rating is called an 'equivalent MERLOT rating'. An overall rating is derived from the average of all the evaluator responses, and separate ratings are derived from each separate category of evaluators to give a comparison in ratings given for each Learning Object when evaluated in different learning contexts. A comparison of the equivalent MERLOT rating for each Learning Object from the three main evaluation groups (MAINZ Tutors, Church Sound Engineers, and MAINZ students) is then made possible. 


\section{Learning Object Design}

The Learning Objects developed and delivered in this research project are digital and software based. Learning Objects can be viewed as small interactive multimedia elements. Commercial multimedia authoring software provides many tools that can be used to develop Learning Objects and deliver them across a variety of platforms, for example Macromedia Flash (Heins \& Himes, 2002). While a range of authoring applications were utilized in the development of the Learning Objects, including: LiveStage Pro, Flash, QuickTime Pro, Dreamweaver, HMTL and JavaScript, QuickTime VR Studio, and Final Cut Pro, the key multimedia format used was QuickTime.

QuickTime (Apple Computer, 2004; Beverly, 2004) was chosen as the architecture for authoring and delivery of the learning objects, for several reasons:

- Cross platform delivery (Macintosh and Windows environments)

- A large installed user base

- Availability of free download and installation of QuickTime

- Ability to create stand-alone interactive objects without requiring the user to buy or learn a proprietary audio programme (e.g. Pro Tools, Logic Audio, Cubase...)

- Support for a wide range of multimedia file formats

- Integration of Macromedia Flash tracks

- Excellent synchronization of multiple audio tracks within a single 'movie'

- Comparable level of interactivity to that of Flash and Director

- Scalability for delivery over different bandwidth formats (Web, 3G mobile devices, CDROM, Hard Drive)

- Integration of time code tracks for synchronization

QuickTime is a track based multimedia architecture. A QuickTime movie can contain over two hundred different media formats, an unlimited number of tracks, and supports a wide range of state of the art compression codecs. It also supports JavaScript, Java, its own scripting language QuickTime script, and is based on XML.

Currently there is only one authoring application that taps the full potential of interactive QuickTime development - LiveStage Pro from Totallyhip Software (2003). This required learning a new authoring application and scripting language, however it is very similar to Flash and Director. These authoring applications were unsuitable (by themselves) for developing the audio related Learning Objects, as they only support eight tracks of audio and provide limited synchronization of tracks. Some of the Learning Objects developed have over twenty-four audio tracks synchronized together within QuickTime.

Using QuickTime allowed certain levels of 'real-time' control and signal processing of the audio examples included in this project. Certain aspects of the learning objects were therefore simulated rather than actual processing of the audio files. More powerful real-time processing could be achieved by writing cross-platform digital signal processing software. This was beyond the expertise and time frame of this study.

Content areas were chosen from the researcher's experience gained from teaching Audio Engineering. The Learning Objects focus upon areas that students generally find difficult to grasp, and are key concepts. Feedback from a survey of potential end users confirmed the choice of topics. Learning Objects were developed that illustrate some of the following concepts in Audio Engineering: operation of an audio mixing desk, achieving an appropriate mix, microphone choice and placement, dynamics processing, and equalization. The learning object interface is presented as a 
floating window on the users desktop (or as an element within an html page if web delivered see Figure 1 for example). This presentation format was chosen rather than a full screen mode, to emphasize the Learning 'Object' concept as a piece of the learning rather than an end in itself (see Figures 1-4 for screenshot examples). The structure of the learning objects is designed for learner investigation, rather than forcing a linear progression through the sections of each.

The graphical interface of the Learning Objects is designed to resemble the actual physical equipment that users would normally be working with. This meant a departure from the graphical designs of commercial audio software and plug-ins, which tend to 'jazz up' their interface elements, to a more 'conservative' graphical representation. In response to user feedback, the first page of each Learning Object opens with the overview and instructions for its use/navigation. Initially the author made the instructions available via a clickable '?' icon, but some users did not associate this with instructions and initially felt lost. Context is established by the images of typical professional quality audio equipment that students actually use within their courses and in live sound environments, and the use of actual audio files recorded using this equipment. Virtual environments are created by using the panoramic and cubic virtual scene capabilities of QuickTime. Text is kept to a minimum as the emphasis is upon recreating an immersive simulated environment, rather than the typical textbook approach. Pedagogy is embedded within each Learning Object by providing opportunities for interactive feedback and formative assessment. For example, in Learning Object 2 (Figure 2), the user selects an example audio mix (from different genres) and then must identify the microphones used in recording the mix by listening to the characteristics of the mix. The 'home' section of this Learning Object provides comparison audio files for the user to practice identifying the characteristic sound of each different microphone. All four Learning Objects can be found on the author's web site (http://ltxserver.unitec.ac.nz/ thom/).

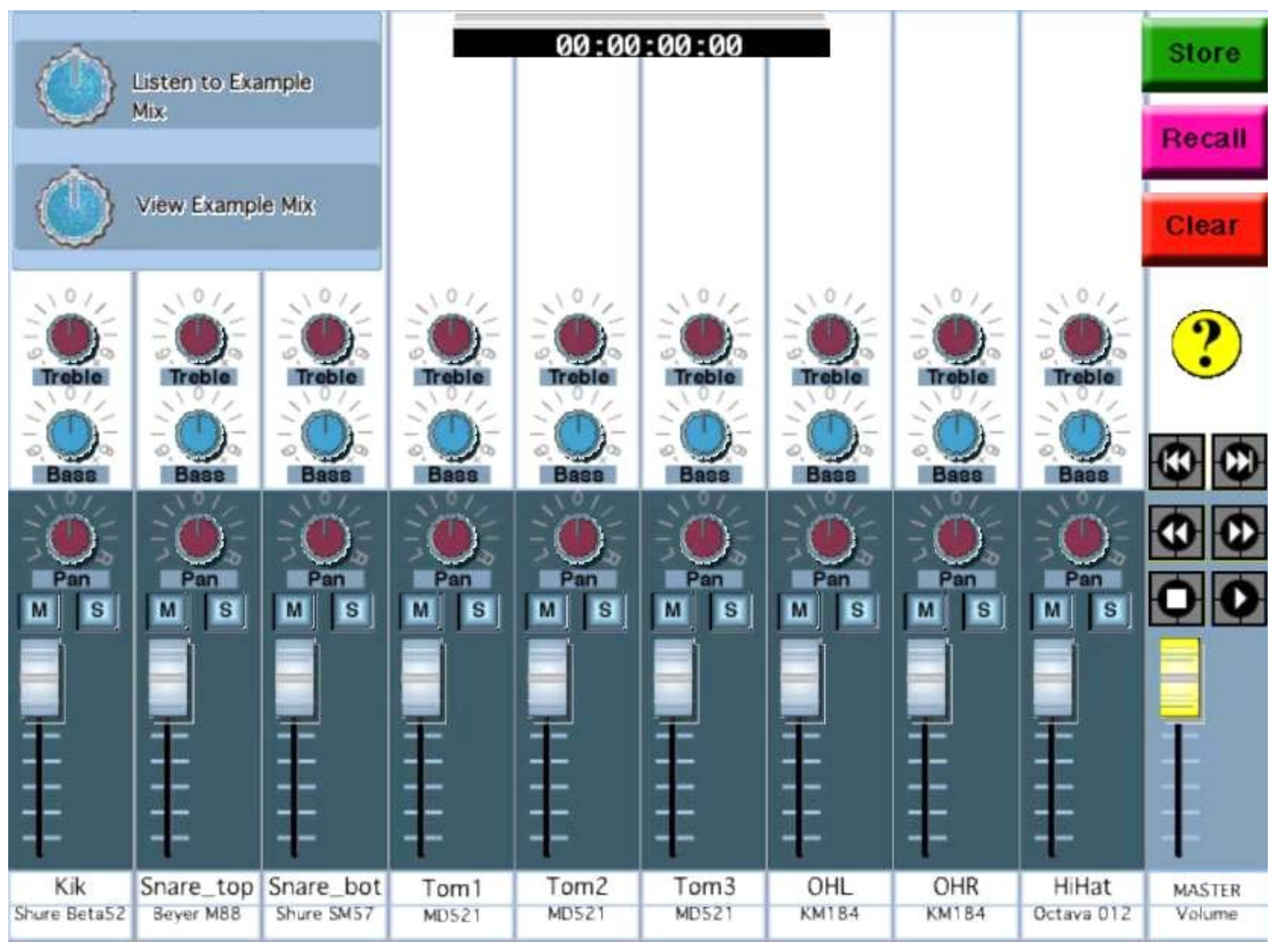

Figure 1. Screenshot of the main window of Learning Object 1 - an interactive audio mixer. 


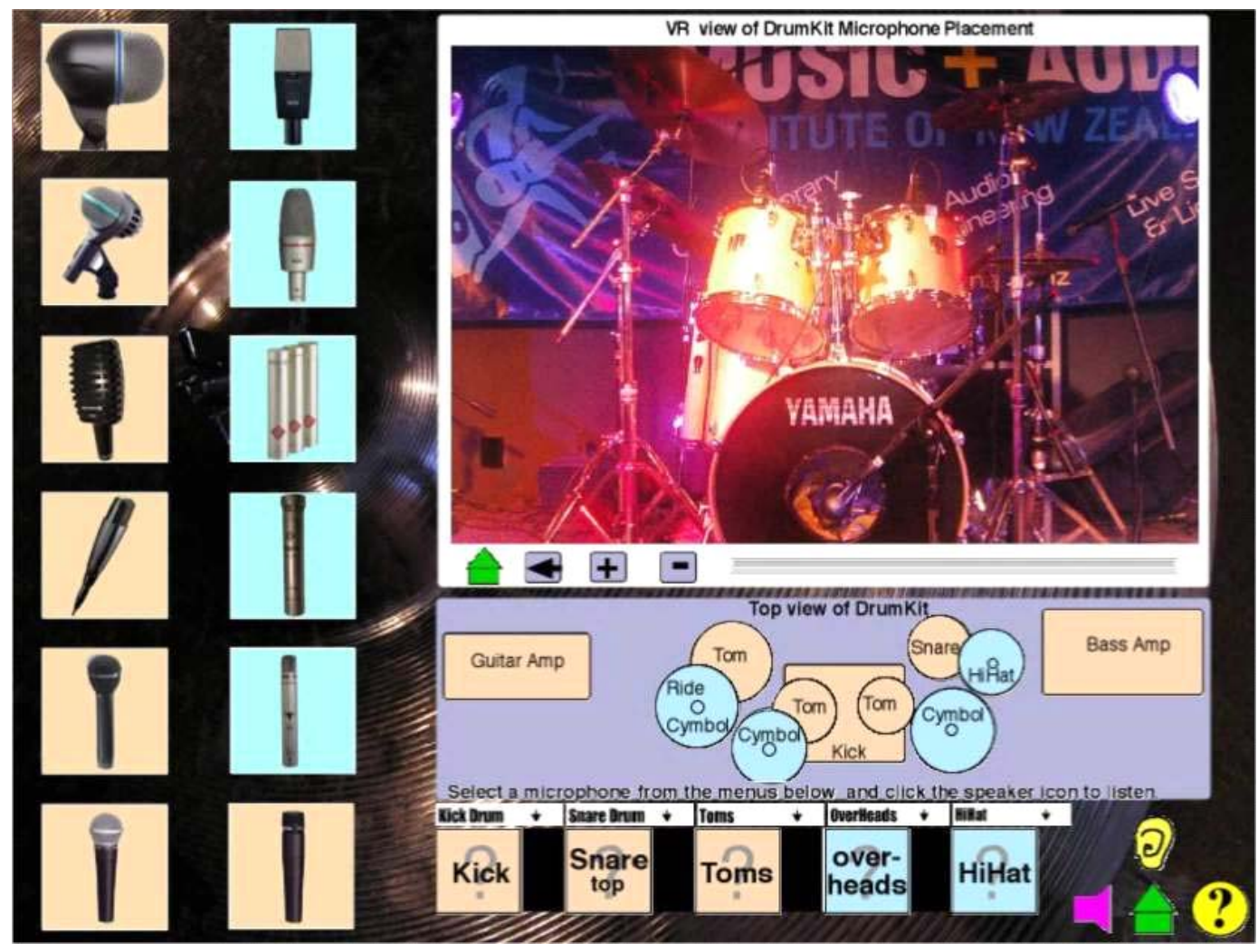

Figure 2. Screenshot of the main window of Learning Object 2 - an interactive microphone chooser.

\section{Learning Object 1 Design}

\section{Description}

Learning Object one is an interactive drum track mixer for learning basic audio mixing principles and ear training.

\section{Learning Outcomes/Objectives}

At the completion of using the Learning Object, students should be able to:

(1). Describe the function of key parameters of an audio mixing desk.

(2). Demonstrate the ability to create an appropriate mix for a multi-track drum-kit.

(3). Critically evaluate an example mix.

\section{Assessment Activities}

The learning object was designed to include simple and flexible formative feedback/assessment. An example mix is provided, that includes audio and visual feedback to the student. Students adjust the parameters of the mixer to see if they can reproduce the example mix. Students also have the capability of creating and saving their own audio mix, which can then be sent to a tutor for feedback. 


\section{Concept}

One of the most basic skills an audio engineer must develop is the ability to operate a mixing desk and use it to produce an appropriate 'mix' (set relative volumes for each instrument, set panning to position instrument within the stereo field, and equalization, set appropriate overall volume via master fader) for a given situation. The Learning Object should provide real time control of these basic parameters with visual and audio feedback.

As this was the first Learning Object developed it also formed a case study in the capability of QuickTime as an authoring and delivery environment to achieve the interactive and crossplatform delivery requirements of the study. The design goal was to provide as much interactivity as possible, and emulate a real analogue audio mixer as closely as possible (within the limitations of the delivery medium).

\section{Learning Object 2 Design}

\section{Description}

This is an interactive microphone chooser/explorer, for learning some basic principles of microphone choice, including audio examples.

\section{Learning Outcomes/Objectives}

At the completion of using the Learning Object, students should be able to:

(1). Choose an appropriate microphone for recording a particular instrument.

(2). Demonstrate appropriate microphone placement for recording or live sound.

(3). Differentiate the sound of different microphones.

\section{Assessment Activities}

In response to evaluation feedback from Learning Object 1, the embedded pedagogy of Learning Object 2 was made more explicit. The learning object was designed to include a simple formative feedback/assessment in the form of an interactive test that is built into the Learning Object. Initial audio examples demonstrate the effect of different microphones used on the same instrument. Six example audio mixes are then provided, from which the student must select the microphone used for each instrument by listening to the characteristics of the recorded sound. A tick box next to the chosen microphone indicates a correct selection.

\section{Concept}

A key skill for a recording or live sound audio engineer is to choose an appropriate microphone for the task. Every instrument has different characteristics and every microphone has characteristics that will match it to a particular instrument or not. Making a good microphone choice will make achieving the style of sound required much easier. A wrong microphone choice can even damage the microphone. Secondly, appropriate placement of the microphone in relationship to the instrument greatly affects the resulting sound. Learning Object two is designed to provide an interactive environment in which to learn these skills. One of the common situations in which multiple microphones are used on one instrument is in the recording of drums. Appropriate placement of microphones around the drum-kit will minimize unwanted noise being recorded, and also minimize phase cancellation problems caused by differences in the length of audio paths to multiple microphones. A drum-kit was chosen as the source for recording multiple microphone sources for this second Learning Object. Using the virtual reality capabilities of QuickTime en- 
abled the creation of a virtual tour of a live sound stage microphone setup, and also links to example studio microphone placement techniques.

\section{Learning Object 3 Design}

\section{Description}

Learning Object three (Figure 3) is an interactive demonstration of the use of parametric equalization, including several audio examples of a variety of different instruments and vocal examples, and a short formative test.

\section{Learning Outcomes/Objectives}

At the completion of using the Learning Object, students should be able to:

(1). Describe the three main parameters of a parametric EQ and how they affect the sound file.

(2). Demonstrate appropriate parametric EQ settings for various instruments.

(3). Evaluate how EQ can enhance the sound of an instrument.

\section{Assessment Activities}

Evaluations of Learning Object 2 indicated that even more explicit assessment be embedded in the Learning Object. Ways of doing this in Learning Object 3 were experimented with. As an interactive simulation, user choices provide feedback visually and audibly. However, real-time control of parametric EQ is not currently possible within QuickTime (or Director or Flash) at the moment, so formative assessment activities were limited to more descriptive type activities in Learning Object three. To keep development time down, the learning component additions to Flash MX were used to create a simple short formative test. As QuickTime supports Flash tracks, it was hoped that the Flash test could simply be embedded within the main QuickTime movie, however QuickTime version 6 does not yet support the learning additions of Flash MX. Therefore the formative assessment was simply linked to the main learning Object movie. This does have the advantage of allowing a tutor to modify the assessment without needing to modify the main Learning object itself, or possibly even provide multiple or alternate assessments.

\section{Initial Concept}

Equalization is a core audio engineering process to enhance, correct problems, and make an instrument stand out in a mix. Learning what frequencies affects what characteristics of an instrument, and how to achieve certain styles of sound is a very important skill. A good audio mixing desk will have several bands of parametric EQ available per channel. Parametric EQ is the most flexible type of EQ, but as such has the most parameters to adjust. Learning Object three is designed to give users an idea of how parametric EQ works and sounds on a variety of different instruments, and suggested 'standard' settings. Audio examples with and without EQ applied can be compared. As QuickTime does not support real-time parametric EQ parameters, the parameters and results will need to be simulated. To add a realistic interface to the Learning Object, audio level meters, and audio waveforms for each example were simulated, providing visual feedback to the user. Snapshots of typical parametric EQ settings were created, based upon the Sony Oxford parametric EQ software plug-in for ProTools. This is a high quality professional EQ with a well laid out graphical interface. The Learning Object was also intended to include a brief overview of graphic equalization, and a short formative test. 


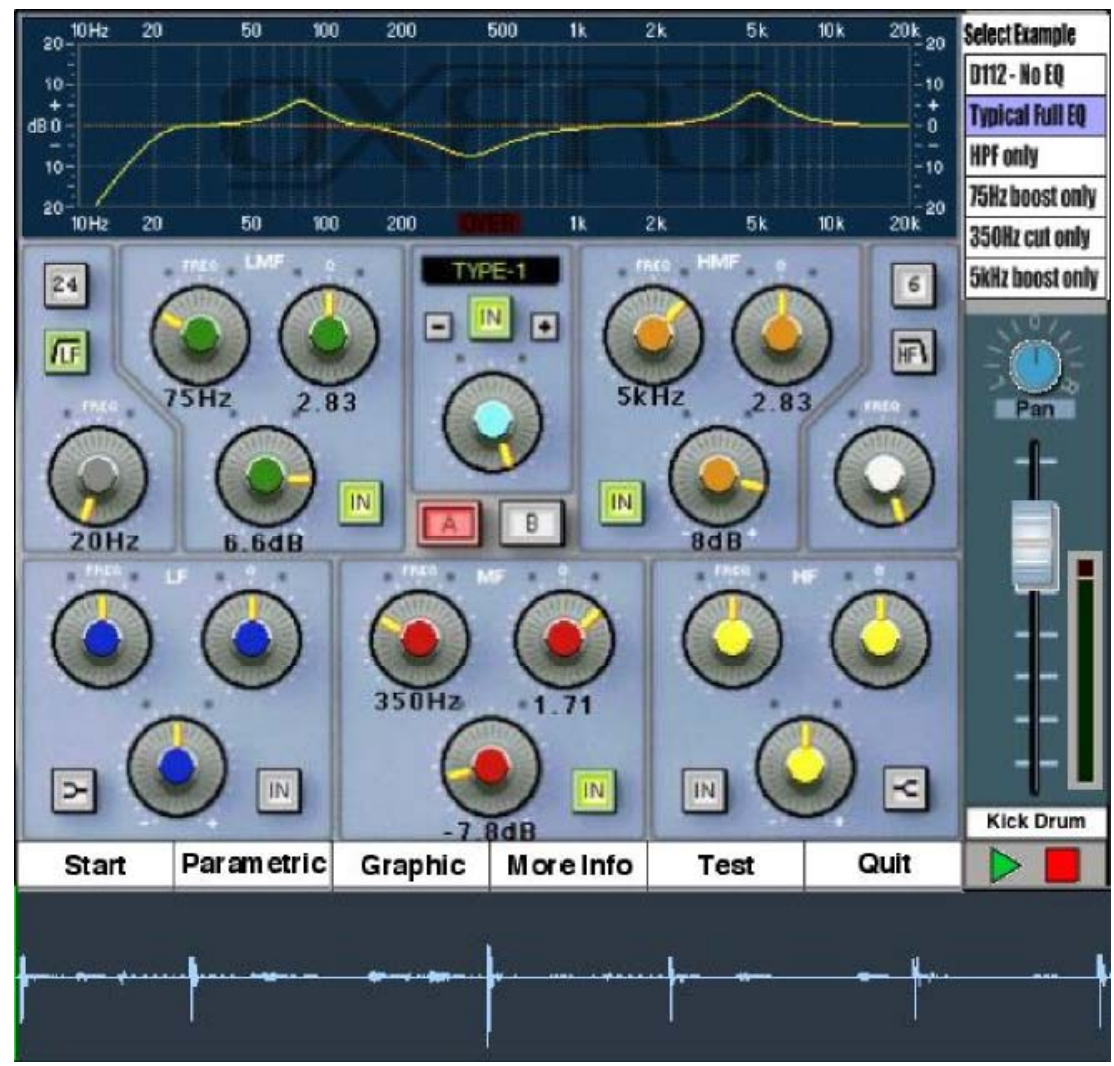

Figure 3. Screenshot of Learning Object 3 - Equalization examples.

\section{Learning Object 4 Design}

\section{Description}

Learning Object four is an interactive demonstration of using compression and gating, including several audio examples, and a short formative test.

\section{Learning Outcomes/Objectives}

At the completion of using the Learning Object, students should be able to:

(1). Describe the main parameters of an audio compressor and gate, and how they affect the sound file.

(2). Demonstrate appropriate compression and gating settings for various instruments.

(3). Evaluate how compression and gating can enhance the sound of an instrument.

\section{Assessment Activities}

The positive response from evaluators to the attached Flash assessments in Learning Object 3 led to utilizing this format again in Learning Object 4. Real-time control of compression and gating is not currently possible within QuickTime (or Director or Flash) at the moment, so formative assessment activities were limited to more descriptive type activities in Learning Object four as in Learning Object three. As with Learning Object three the formative assessment was simply linked to the main Learning Object movie. This does have the advantage of allowing a tutor to modify 
the assessment without needing to modify the main Learning object itself, or possibly even provide multiple or alternate assessments.

\section{Concept}

Dynamics control and manipulation is another core aspect of audio engineering, and an area where users generally need significant training. The goal was to produce a virtual environment to model appropriate use of compression and gating settings for various instruments. The design started with a brainstorm of capability and interface ideas, based upon actual studio dynamics processing equipment. To illustrate the concepts, interface elements from both traditional analogue equipment, and the more conceptual elements from software plug-ins were chosen. These included standard controls, level meters, simulated waveforms, and input/output graphs. Audio examples with and without compression or gating applied were to be included to provide audible comparisons. (Figure 4.)

User feedback from Learning Object three indicated that the users wanted more interactive control over the Learning Object parameters than was provided. The limitation is the lack of realtime digital signal processing capability of QuickTime. To address this in Learning Object four, a similar design approach (simulation) was taken as in Learning Object three, but the interface knobs were made to move between selected settings, rather than selecting complete snapshots of the Learning Objects, and the comparison between unaffected and effected audio examples is selected by turning the effect 'on' (clicking on the 'on' button). This added dynamic visual element proved worthwhile in conveying a more immersive virtual environment that operates similar to real world equipment.

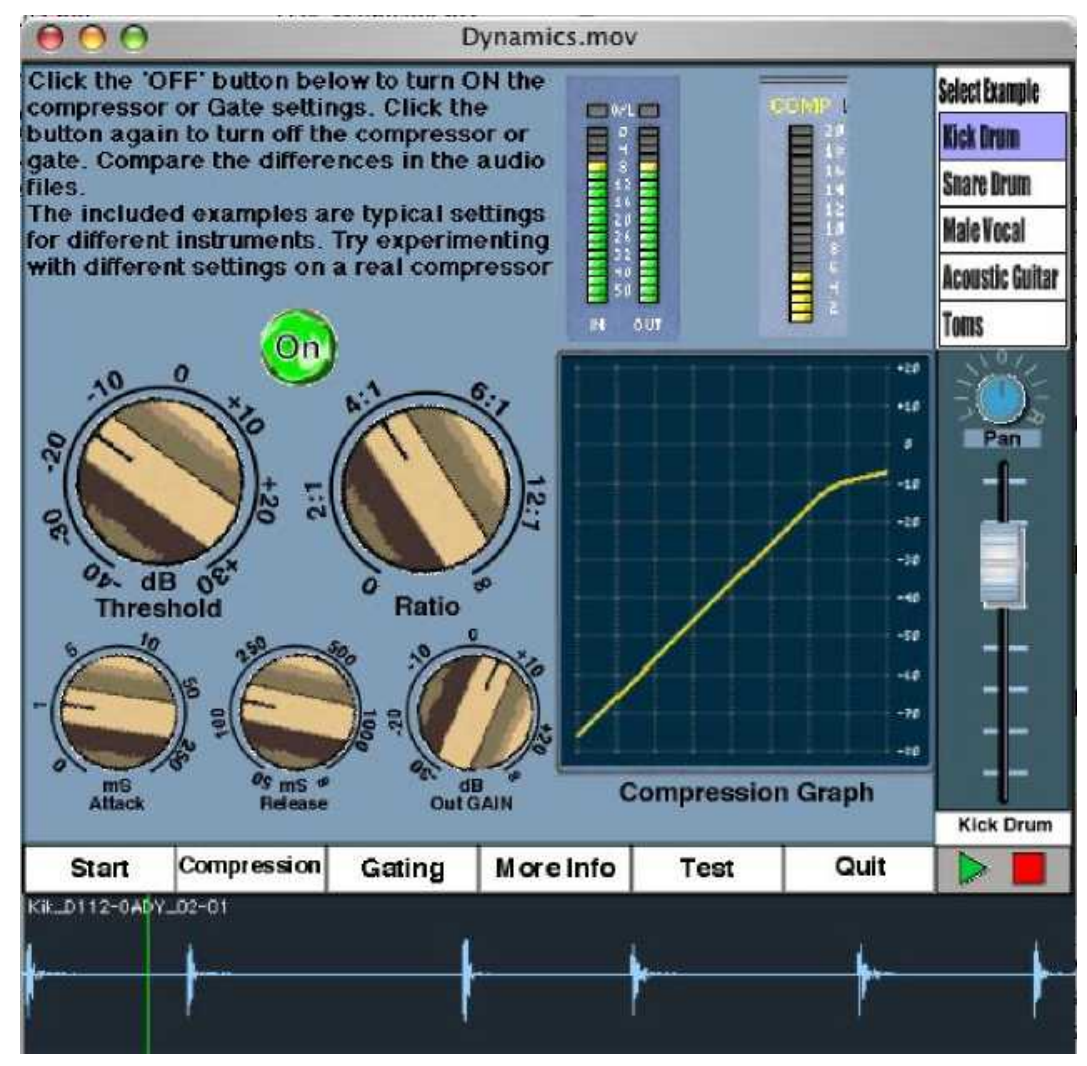

Figure 4. Screenshot of Learning Object 4 - Dynamics examples. 


\section{Learning Object Evaluation}

Below are the average equivalent MERLOT ratings for each Learning Object from all evaluators.

Learning Object 1 Evaluation, MERLOT equivalent rating = 3.95

Learning Object 2 Evaluation, MERLOT equivalent rating $=4.20$

Learning Object 3 Evaluation, MERLOT equivalent rating $=4.12$

Learning Object 4 Evaluation, MERLOT equivalent rating $=4.24$

These results indicate that the Learning Objects were generally highly rated by all users. On the MERLOT rating criteria the results of evaluation of all four Learning Objects indicates "materials are very good overall but there are a few minor concerns" (MERLOT, 2000). By investigating and implementing constructivist design strategies for Learning Objects before developing the Learning Objects the project produced quality Learning Objects that did not require radical changes, but rather optimizing and polishing. The design and development processes were informed by current educational technology research.

Below are example summaries (Figures 5 to 9 ) of user feedback gathered from the modified MERLOT evaluation form for the Learning Objects. The charts give a quick indication of a comparison between the main contexts within which the Learning Objects were evaluated.

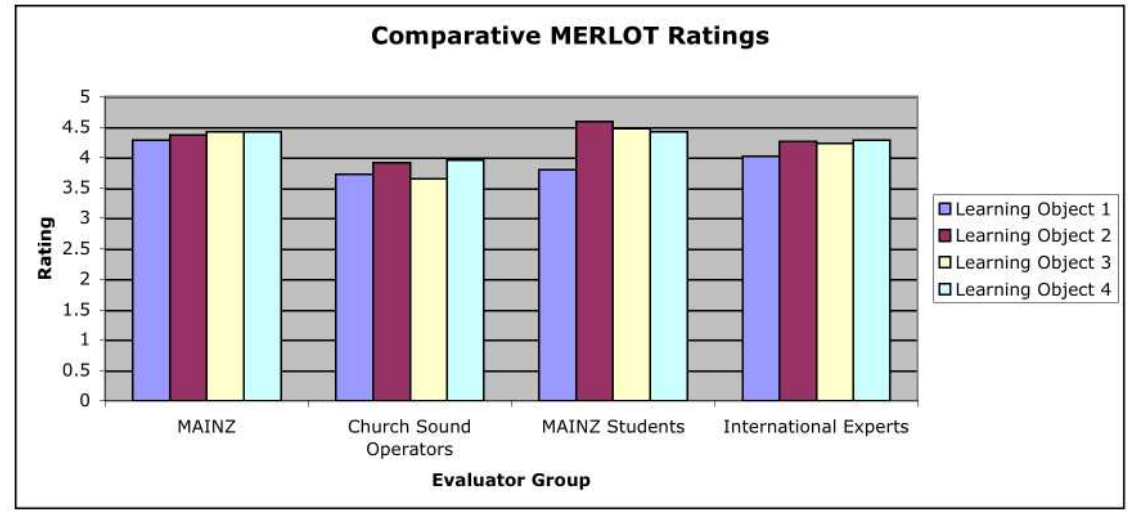

Figure 5. Comparison of equivalent MERLOT Ratings for all Learning Objects.

The Learning Objects did achieve a progression of increasing quality in terms of users evaluation, even though the last two Learning Objects pushed the boundaries of the interactive possibilities within the QuickTime environment. The developer learnt valuable lessons from the design of each consecutive Learning Object. The 'dip' in evaluations ratings for Learning Object three reflected the expectation of a higher level of user control and interaction with the virtual environment that had been built up by the first two Learning Objects. The technical limitations of the QuickTime authoring environment meant that this interaction had to be simulated. This was achieved more successfully in Learning Object four. More time available for development would allow a higher level of user control of parameters to be simulated within the Learning Objects.

The least experienced evaluators (church sound engineers and MAINZ students) ratings varied more significantly between the four Learning Objects than those of the 'experts' (MAINZ tutors and international experts). This indicates that these users value different aspects of the Learning Objects. The less experienced users were more concerned with the interface and graphics, while the MAINZ tutors and international experts were more focused on the pedagogy of the Learning Objects. 
The adoption of the MERLOT criteria for evaluating Learning Objects provided a tried and tested starting point for the Learning Object evaluation instrument. Rather than re-inventing the wheel, the MERLOT criteria check list was modified for the context of this study. The three MERLOT evaluation categories: quality of reusability, quality of interactivity, and effectiveness as a teaching tool, aligned perfectly with the research project. The peer review process also ensured a scholarly approach to the evaluations. However, as Nesbit, Belfer and Vargo (2002) pointed out, the main problem with peer review processes, such as the MERLOT evaluation process, is the time involved in waiting for the reviews to be returned. This time lag limited the number of Learning Objects that could be evaluated over the time span of the project. One evaluation per semester was all evaluators were willing to undertake. In selecting reviewers, some form of mutual contact with the researcher needed to be established for reviewers to agree to participate. This was not a problem for this study, as the researcher was a colleague of the MAINZ reviewers, and had established relationships with most of the church sound engineers, but it could present a problem for other projects where there was not this initial contact.

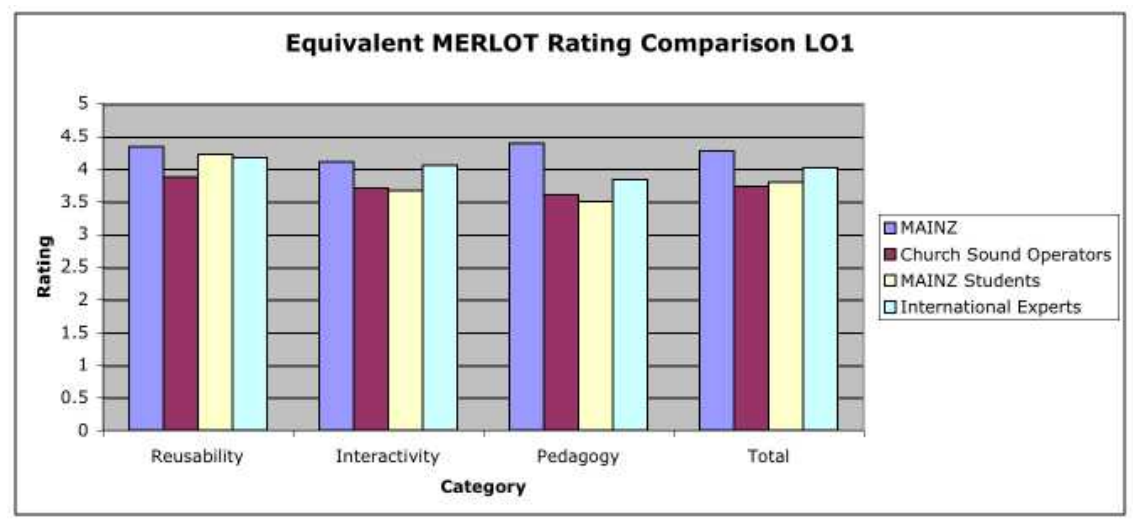

Figure 6. Summary of equivalent MERLOT Ratings for Learning Object 1.

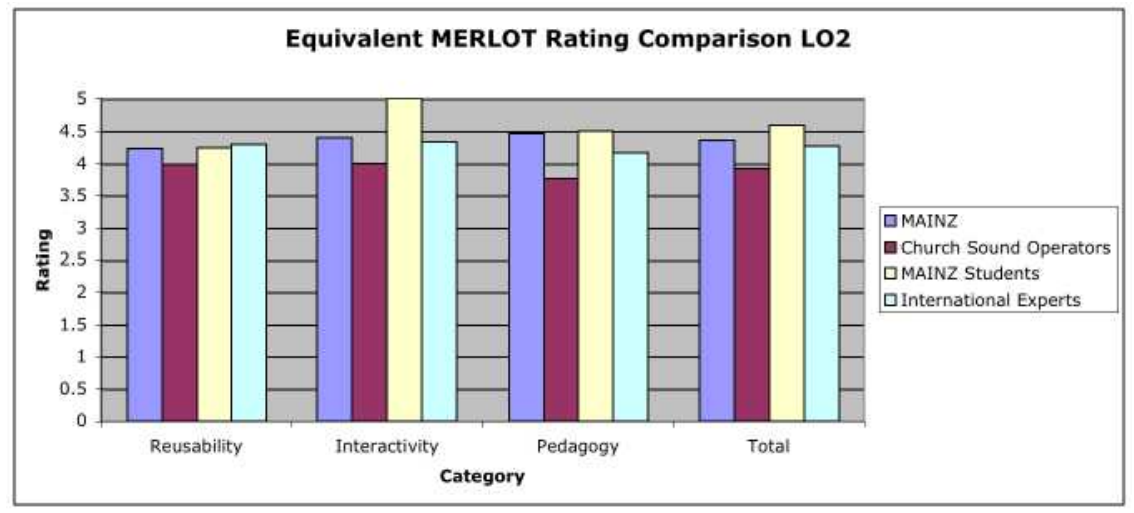

Figure 7. Summary of responses to evaluation questions for Learning Object 2. 


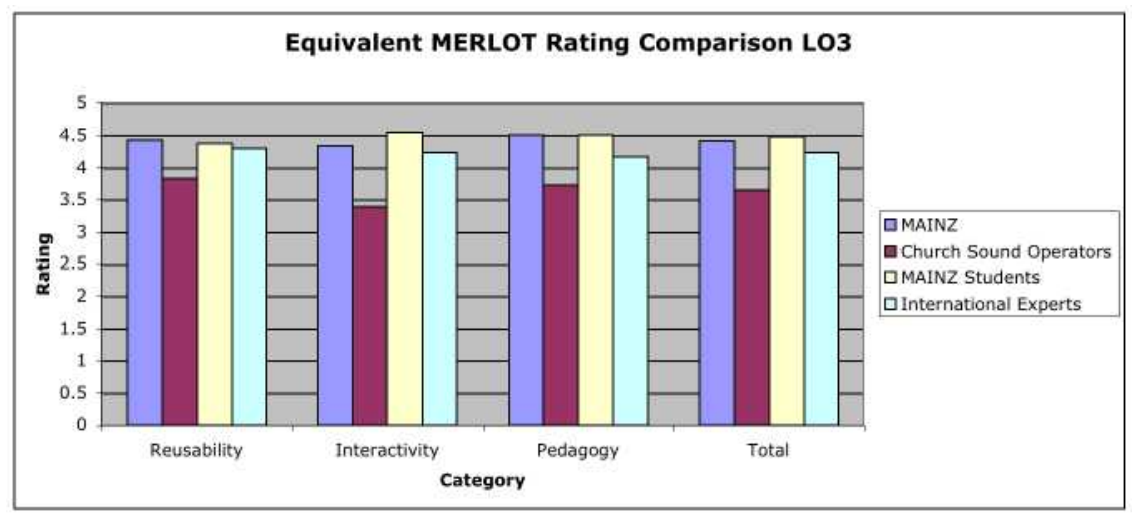

Figure 8. Summary of responses to evaluation questions for Learning Object 3.

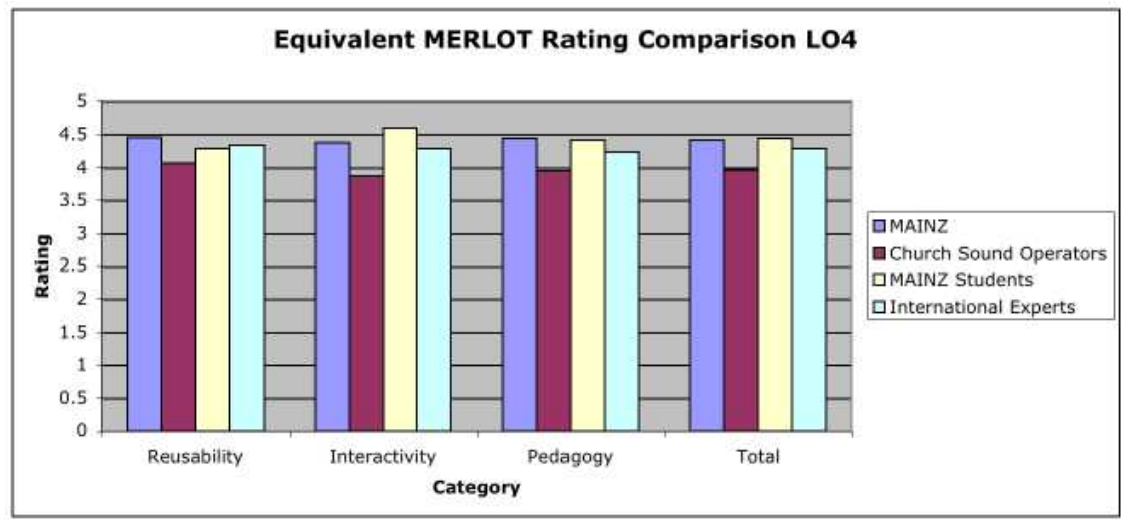

Figure 9. Summary of responses to evaluation questions for Learning Object 4.

Feedback on the functionality and interface focused upon extending the functionality, adding a wider choice of audio tracks, and 'modernizing' the 'look'. Most users were satisfied with the level of interactivity available within the QuickTime architecture. Feedback from international evaluators indicated a very positive response to the Learning Objects. Overall there has been a very positive response from users to the learning objects developed so far. Some tutors began to see the possibility of teaching audio principles on-line.

\section{Answering the Research Questions}

The research project intended to address two research questions.

(1). What are the key factors in designing Learning Objects that are reusable for learning concepts in Audio Engineering - a discipline that traditionally teaches these concepts in a 'face-to-face' 'hands-on' mode?

The research project has demonstrated the development and evaluation of four Learning Objects that covered four key concepts within Audio Engineering that are usually taught 'hands-on'. These Learning Objects received very positive evaluations from tutors of five different audio engineering courses, as well as church sound operators from five different churches in Auckland. The Learning Objects were demonstrated to be effective in these different learning contexts. Representative Audio Engineering students, and international experts also gave the Learning Objects good evaluations. The potential for the Learning Objects to be used within other learning contexts 
has been expressed by the evaluators. The optimum scenario for the use of the Learning Objects is complimenting other methods of learning rather than a complete replacement of face-to-face teaching. The key factors in the design of these Learning Objects were found to be: clearly defining the learning objectives, choosing an appropriate multimedia architecture, simulating real world activities/equipment, providing high levels of user interactivity, embedding formative assessment into the Learning Objects, and utilizing a participant-oriented evaluation within the design cycle.

(2). To what extent can these Learning Objects support learner interactivity and interest, and thus provide pedagogically rich learning environments that engage and motivate the learner?

Using the QuickTime architecture, a high level of interactivity within the Learning Objects was possible, including real-time control of many audio parameters. Audio parameters that were inaccessible directly via QuickTime were simulated within the QuickTime environment. The user evaluations emphasized the high value that interactivity and user control within the Learning Objects is given. Emulating a real world environment and Audio Engineering equipment was highly valued. The ability to experiment and learn within a safe simulated environment was also highly valued. All the evaluators agreed that the Learning Objects were successful in enhancing the users ability to learn the Audio Engineering concepts covered. The inclusion of formative assessment provided opportunities for users to test their understanding of the concepts. The level of assessment could be increased for future Learning Objects or added to the current Learning Objects. The Learning Objects successfully augmented traditional methods of learning audio engineering concepts.

\section{Conclusions}

Development of the Learning Objects took a lot longer than initially anticipated. Features and interactivity were constrained by the available development time. However, the choice of QuickTime as architecture, and the implementation of instructional design principles provided the basis for developing interactive Learning Objects that successfully enhanced the learning of a wide range of users at different levels and in different contexts. The QuickTime environment allowed a high level of user interaction without requiring high level programming knowledge from the developer, thus keeping the development at a more creative rather than technical level.

Implementing a participant-oriented evaluation process within the design cycle of the Learning Objects provided useful feedback on their effectiveness and areas for modification and improvement. Interactivity and learner control of the Learning Objects were highly valued by evaluators.

Trained educators managed to see the pedagogical possibilities of the Learning Objects better than the Church sound operators. This is expected, as modifying an educational context does require expertise (otherwise Learning Objects could replace tutors). Thus the role of educators to embed the Learning Objects within a larger learning context is crucial.

The utilization of action research produced a research project that has real world tangible results that will benefit the researcher's educational practice, and the wider field of Audio Engineering within New Zealand. Future recommendations for the study include building into the design and evaluation process evaluations of the Learning Objects from a wider range of users e.g. from international audio courses right from the beginning of the project.

Recommendations for interactive multimedia Learning Object development are:

- Make operator instructions and learning outcomes clear and explicit

- Provide multiple assessment options that educators can choose to link to each Learning object. 
- Provide as high a level of user interactivity as possible

- Include participant-oriented evaluation as an integral part of the design process

- Emulate real world environments as closely as possible

- Choose a multimedia architecture that meets the key project requirements

- Allow plenty of time for development and evaluation

- Provide training for educators to develop the skills to embed the Learning Objects within the wider learning environment and thus maximize the learning potential of Learning Objects

Learning Objects have the potential to enhance learning, but what is needed is a commitment from tertiary institutions to not only research this field, but to also develop and share quality Learning Objects for the Learning Object economy to become a reality.

Learning objects are at a turning point. There is an opportunity to create a diverse, global network of learning object developers, repositories, and users who, if they can effectively organize and coordinate their activities, will be able to produce a library of high-quality, pedagogically sound, free (or inexpensive) materials that will make all of the investments in infrastructure pay off in the educational experience for students (Roy, 2004a, pg. 82).

\section{References}

Apple Computer. (2004). Why QuickTime? Retrieved from http://www.apple.com/quicktime/whyqt/

Bannan-Ritland, B., Dabbagh, N., \& Murphy, K. (2000). Learning object systems as constructivist learning environments: Related assumptions, theories, and applications. In D. Wiley (Ed.), The Instructional Use of Learning Objects. Bloomington: Association for Educational Communications and Technology.

Bennett, K., \& Metros, S. (2001, Oct. 21). Learning object/module checklist. Retrieved 23 February, 2003, from http://itc.utk.edu/educause2001/checklist.htm

Beverly, B. (2004, 4 March). QuickTime: The on-line, cross-platform, multimedia architecture of the present and future. Retrieved June 2004, from http://www.wright.edu/ctl/media/multimedia/quicktime.html

Douglas, I. (2001, October). Instructional design based on reusable learning objects: Applying lessons of object-oriented software engineering to learning systems design. Paper presented at the 31st ASEE/IEEE Frontiers in Education Conference, Reno, NV.

Downes, S. (2003). Design and reusability of learning objects in an academic context: A new economy of education? United States Distance Learning Association Journal, 17 (1), 3-22

Everest, F. A. (1997). Critical listening and auditory perception: The complete audio-visual training course. On Mix Pro Audio Series (Everest). Emeryville: MixBooks. [Includes CD of audio examples]

Gibson, B. (2000). AudioPRO recording courses. Retrieved 29 January, 2003, from http://www.artistpro.com/audioPROcourses.cfm

Hambly, C. (2002, 1 September). Audio courses. Retrieved 3 December, 2002, from http://www.audiocourses.com

Hanley, G. (2003, June 1). Online resource: MERLOT: Peer-to-peer pedagogy. Syllabus.

Heins, T., \& Himes, F. (2002, April). Creating learning objects with Macromedia Flash MX. Retrieved 1 February, 2003, from http://download.macromedia.com/pub/solutions/downloads/elearning/flash_mxlo.pdf 
Hoepfl, M. (1997). Choosing qualitative research: A primer for technology education researchers. Retrieved 19 April, 2002, from http://www.scholar.lib.vt.edu/ejournals/JTE/v9n1/hoepfl.html

Johnson, L. (2003). Elusive vision: Challenges impeding the learning object economy. Retrieved September, 2004, from http://download.macromedia.com/pub/solutions/downloads/elearning/elusive_vision.pdf

Koch, T., \& Borell, M. (1997, 17 March). Dublin core metadata template. Retrieved July, 2003, from http://www.lub.lu.se/metadata/DC_creator.html

Mellor, D. (2001). Audio masterclass: Distance learning for sound engineering \& music production. Retrieved 12 March, 2003, from http://www.audiomasterclass.com/index.html

Mellor, D. (2003). Record-Producer.com. Retrieved 12 March, 2003, from http://www.recordproducer.com

MERLOT. (1997). MERLOT: Multimedia educational resource for learning and online teaching. Retrieved 13 May, 2002, from http://www.merlot.org

MERLOT. (2000, November 27). Evaluation standards for learning materials in MERLOT. Retrieved 23 February, 2003, from http://taste.merlot.org/eval.html

Nesbit, J., Belfer, K., \& Vargo, J. (2002). A Convergent Participation Model for Evaluation of Learning Objects. Canadian Journal of Learning and Technology, 28 (3).

Neumann, G. (1996). Sound Engineering Contest 1998 [CDROM]. Berlin: Georg Neumann.

Roy, M. (2004a). Learning Objects. EdUCAUSE Review, 39 (6), 80-84.

Roy, M. (2004b). Overview of Learning Objects. Educause Evolving Technologies Committee.

SAE Institute. (2001). Reference material center. Retrieved 13 May, 2002, from http://www.saecollege.de/reference_material/index.html

Sides, A. (1995). Allen Sides' microphone Cabinet [CDROM]. Emeryville: Cardinal Business Media Inc.

Totally Hip Software. (2003). LiveStage Pro. Retrieved from http://www.totallyhip.com/livestage.asp

Wadsworth, Y. (1998). What is participatory action research? Retrieved May 3, 2002, from http://www.scu.edu.au/schools/gcm/ar/ari/p-ywadsworth98.html

Wiley, D. (2002). Learning Objects - A definition. In A. Kovalchick \& K. Dawson (Eds.), Educational Technology: An Encyclopedia. Santa Barbara: ABC-CLIO.

Williams, D. D. (2000). Evaluation of learning objects and instruction using learning objects. In D. Wiley (Ed.), The Instructional Use of Learning Objects. Bloomington: Association for Educational Communications and Technology.

\section{Appendix 1 \\ Learning Object/Module Evaluation}

(Adapted from the MERLOT Module Review Form (MERLOT, 2000) and (Bennett \& Metros, 2001)) The information gathered from this questionnaire will be confidential and anonymous, and will be used solely for the purposes of a research Thesis for the MComp at Unitec.

\section{Learning Object/Module Title:}

Brief description:

Location/URL: 


\section{Learning Goal:}

Target audience:

\section{Reviewer Details:}

Circle one: MAINZ Student, MAINZ Tutor, Sound Operator

Course:

Location:

\begin{tabular}{|l|l|l}
\hline Contact (optional) Email: & Name: & Phone:
\end{tabular}

\section{Some Definitions:}

Learning Object: “Any digital resource that can be reused to support learning. The term "learning objects" generally applies to educational materials designed and created in small chunks for the purpose of maximizing the number of learning situations in which the resource can be utilized.” (Wiley, 2002)

Reusability: The ability to use a learning object within different learning contexts.

Pedagogy: "the activities of educating or instructing or teaching ;activities that impart knowledge or skill” (HyperDictionary, 2003)

System Requirements: You will need a PPC Macintosh OR Pentium Windows computer, with a CD quality sound card, 1024 by 768 colour monitor, and QuickTime 6 installed (http://www.apple.com/quicktime)

Tick the appropriate column for each statement.

\begin{tabular}{|c|c|c|c|c|c|c|c|}
\hline & Reusability & 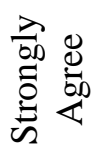 & 恖 & 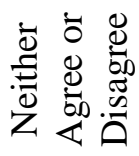 & Disagree & 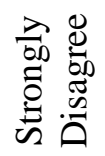 & $\overleftrightarrow{\Sigma}$ \\
\hline & & 5 & 4 & 3 & 2 & 1 & \\
\hline A & $\begin{array}{l}\text { The Learning Object is clear and } \\
\text { concise }\end{array}$ & & & & & & \\
\hline B & Demonstrates a core concept & & & & & & \\
\hline C & Is relevant to Audio Engineering & & & & & & \\
\hline $\mathrm{D}$ & Provides accurate information & & & & & & \\
\hline E & $\begin{array}{l}\text { Can be used in different learning } \\
\text { contexts }\end{array}$ & & & & & & \\
\hline $\mathrm{F}$ & $\begin{array}{l}\text { Is easily available in different for- } \\
\text { mats (e.g. web, CD, HD, Windows, } \\
\text { Mac) }\end{array}$ & & & & & & \\
\hline G & Summarizes the concept well & & & & & & \\
\hline
\end{tabular}




\begin{tabular}{|l|l|l|l|l|l|l|l|}
\hline H & $\begin{array}{l}\text { The Learning Object is customiza- } \\
\text { ble }\end{array}$ & & & & & & \\
\hline I & Comments/Improvements: \\
\hline
\end{tabular}

\begin{tabular}{|c|c|c|c|c|c|c|c|}
\hline & Quality of Interactivity & 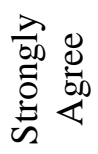 & 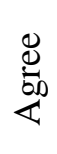 & 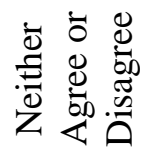 & Disagree & 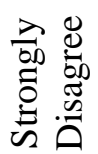 & $\frac{\mathbb{Z}}{\mathrm{Z}}$ \\
\hline & & 5 & 4 & 3 & 2 & 1 & \\
\hline A & Is easy to use & & & & & & \\
\hline B & Has very clear instructions & & & & & & \\
\hline $\mathrm{C}$ & Is engaging - interesting to use & & & & & & \\
\hline $\mathrm{D}$ & Is visually appealing & & & & & & \\
\hline $\mathrm{E}$ & Emulates a realistic environment & & & & & & \\
\hline $\mathrm{F}$ & Provides feedback to the user & & & & & & \\
\hline G & Comments/Improvements: & & & & & & \\
\hline
\end{tabular}

\begin{tabular}{|c|c|c|c|c|c|c|c|}
\hline & $\begin{array}{l}\text { Potential effectiveness } \\
\text { as a teaching tool }\end{array}$ & 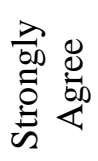 & 离 & 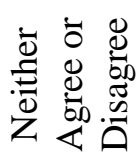 & Disagree & 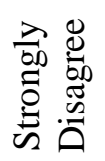 & 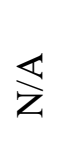 \\
\hline & & 5 & 4 & 3 & 2 & 1 & \\
\hline $\bar{A}$ & $\begin{array}{l}\text { Supports a variety of learning ob- } \\
\text { jectives }\end{array}$ & & & & & & \\
\hline B & $\begin{array}{l}\text { Is effective in increasing under- } \\
\text { standing of the concepts }\end{array}$ & & & & & & \\
\hline $\mathrm{C}$ & Reinforces concepts progressively & & & & & & \\
\hline $\bar{D}$ & $\begin{array}{l}\text { Provides opportunities for forma- } \\
\text { tive or summative assessment }\end{array}$ & & & & & & \\
\hline $\bar{E}$ & $\begin{array}{l}\text { Can be used to demonstrate rela- } \\
\text { tionships between concepts }\end{array}$ & & & & & & \\
\hline $\mathrm{F}$ & $\begin{array}{l}\text { Is very efficient (one can learn a lot } \\
\text { in a short period of time) }\end{array}$ & & & & & & \\
\hline $\bar{G}$ & Comments/Improvements: & & & & & & \\
\hline
\end{tabular}




\section{Appendix 2 \\ Focus Group Questions}

1. How would you rate the effectiveness of the Learning Object for increasing your/your students understanding of the topic?

2. How realistic was the interface of the Learning Object?

3. How customizable/flexible did you find the Learning Object?

4. How context specific did you find the learning objects?

5. Describe how the Learning Objects may be improved.

6. (For Tutors) How would you rate the usefulness of the Learning Objects for your own teaching?

7. What level of interactivity did the Learning Objects provide?

8. What was your experience of utilizing QuickTime as the Learning Object format?

9. Were the system requirements for the Learning Objects easily met?

10. How easy to understand was the language used in the Learning Objects?

11. How could the description (metadata) of the Learning Objects be improved?

12. In what situations would the Learning Objects be most effective?

13. What opportunities exist for using the learning objects to provide formative assessment?

\section{Biography}

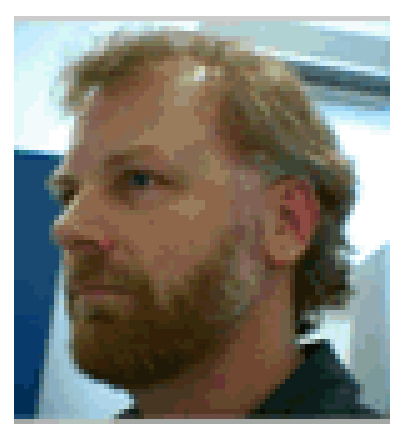

Thomas Cochrane is an e-learning and Learning Technologies Coordinator at Unitec, New Zealand. His role at Unitec includes providing support for e-learning and learning technologies for Unitec teaching staff, and pushing the boundaries of educational technology for enhancing teaching and learning at Unitec. Previously (1997 to 2004) he was a Tutor of Audio Engineering and Music Production at the Music and Audio Institute of New Zealand, where he specialized in digital recording, loudspeaker design and multimedia production. While at MAINZ he developed their elearning environment, website, wireless network, and developed a range of interactive multimedia learning objects. 